\title{
Trade-offs between storage and survival affect diapause timing in capital breeders
}

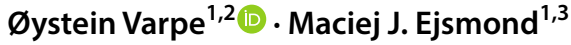

Received: 4 July 2018 / Accepted: 16 October 2018 / Published online: 10 November 2018

(c) The Author(s) 2018

\begin{abstract}
Many organisms spend the unfavourable part of the year, such as the winter season, in diapause or dormancy and reproduce in spring shortly after emergence. Reserves are acquired prior to diapause to cover metabolic costs and in some species also reproduction (capital breeding) directly after diapause. Storage is then a component of future reproduction, and capital breeders consequently pay a pre-breeding cost of reproduction as they risk dying while obtaining and carrying the reserves. How large should the reserves be, and to what extent should optimal storage, and thereby timing of diapause, depend on predation risk and reproductive strategy? We present a general and simplistic life history model of an arthropod (e.g. crustaceans or insects) that is exposed to background mortality risk when it accumulates reserves before diapause. The model optimizes diapause timing and resultant reserves for income, mixed and capital breeders, and predicts how mortality risk affects the degree of capital breeding. For income breeders, timing of diapause is insensitive to the risk while obtaining reserves as they, regardless of risk, acquire the minimum amount needed to survive the winter. For capital breeders, the higher the risk the earlier the diapause and less is consequently stored. Mixed breeders diapause late and store as much as pure capital breeders when exposed to low risk, but behave as income breeders and diapause early when mortality is high. Our model shows that the degree of capital breeding impacts phenology of diapause in a risk-dependent manner. This prediction should impact how diapause timing is thought of across a wide range of taxa, including the much studied marine copepods. Timing of diapause, including triggers and cues, can only be understood when the diversity of reproductive strategies and the adaptive value of storage is taken into account.
\end{abstract}

Keywords Energy reserves · Life-history theory $\cdot$ Predation risk · Resource allocation · State-dependence $\cdot$ Income breeding

Electronic supplementary material The online version of this article (https://doi.org/10.1007/s1068 2-018-9961-4) contains supplementary material, which is available to authorized users.

Øystein Varpe

oystein.varpe@unis.no

1 Department of Arctic Biology, The University Centre in Svalbard, 9171 Longyearbyen, Norway

2 Akvaplan-niva, Fram Centre, 9296 Troms $\varnothing$, Norway

3 Institute of Environmental Sciences, Jagiellonian University, 30-387 Kraków, Poland 


\section{Introduction}

Organisms have evolved a large arsenal of adaptations to both sense and avoid predators and other risks. Understanding the risk-sensitivity of animal behaviors and life strategies is a central challenge in evolutionary ecology (Lima and Dill 1990; Werner and Anholt 1993; Houston and McNamara 1999). Life history theory shows that trade-offs that involve risk, and therefore survival, can be understood when translated into fitness gains, or more precisely, current and residual reproductive success (Williams 1966; Stearns 1992; Roff 2002). For example, current production of offspring is weighed against parental survival, which in turn determines the potential for future reproduction (Drent and Daan 1980; Ydenberg 1989; Reznick et al. 1990; Ghalambor and Martin 2001). We investigate how different levels of risk impact the trade-off between survival and storage (accumulation of reserves), where storage can be viewed as a component of future reproduction. We are interested in how this trade-off is solved differently for reproductive strategies that range from income to capital breeding, and how this trade-off impacts the degree of capital breeding itself. Income breeders base reproduction on current food intake whereas capital breeders rely on reserves stored prior to breeding, in seasonal environments often the year before (Jönsson 1997; Varpe et al. 2009). Consequently, for capital breeders, storage is an investment in future reproduction and we would expect the amount of reserves accumulated to depend on the risk involved in obtaining them.

Internal body reserves (typically as lipids and proteins) is a key trait of many life histories, particularly for organisms in environments with a seasonal food source (Varpe 2017). Reserves are often considered an energy buffer needed for survival of unpredictable times (Fischer et al. 2011; Giacomini and Shuter 2013) or to cover maintenance costs during periodical shortage of food such as a winter season or diapause (Giacomini and Shuter 2013). Such a view of storage is valid for income breeders, but does not capture the selective forces acting upon capital breeders which through storage indirectly invest in reproduction long before the fitness payoff is released as offspring (Jönsson 1997; Varpe et al. 2009). Capital breeders consequently pay a pre-breeding cost of reproduction as they risk dying while obtaining and carrying the reserves.

The timing of annual activities, such as diapause, migrations, reproduction and storage, has fitness consequences, linking phenology and life-time perspectives (McNamara and Houston 2008; Forrest and Miller-Rushing 2010; Varpe 2017). Our work investigates the phenology consequences brought by risk-driven optimization of storage strategies. We focus on diapause (or dormancy) which is a common adaptation to seasonal food availability (Cohen 1970; Tauber et al. 1986; Varpe 2012). Building reserves takes time and capital breeders therefore need to forage for longer than income breeders before they enter diapause. The difference in time used for storage would in turn impact the onset of diapause timing. Fitness consequences of diapause timing must therefore be considered in relation to how the storage-survival trade-off depends on breeding strategy.

Many marine and terrestrial arthropods have evolved diapause or some level of dormancy, yet their reliance on reserves for reproduction is highly diverse. Some are pure capital breeders (Miller et al. 1984; Tammaru and Haukioja 1996), but a mixed breeding strategy that combines income with some degree of capital breeding is common, as for insects (Jervis et al. 2008; Javoiš et al. 2011; Kivelä et al. 2012) and marine crustaceans (Hagen and Schnack-Schiel 1996; Rey-Rassat et al. 2002; Daase et al. 2013). There is growing interest in the ultimate drivers that position the breeding strategy on an income to capital breeding continuum. Seasonality in offspring contribution to fitness, high rate of food 
supply from mother to offspring, low predation risk in seasonal environments, stochasticity in food availability, or allometric scaling of metabolism with body size are among the drivers selecting for capital breeding (Reznick and Braun 1987; Houston et al. 2007; Stephens et al. 2009; Varpe et al. 2009; Ejsmond et al. 2015, 2018). We need studies of how the amount of reserves acquired depends on the mortality risk during the acquisition period, and how the degree of capital breeding interacts with other components of the annual routine, such as timing of diapause or seasonal migrations.

One inspiration for our work is the diapause and reproductive strategies of copepods in high latitude marine ecosystems and the discussion about cues and drivers of timing of diapause and the accompanying seasonal migrations. Seasonal deep-water diapause is part of the annual routine for a range of abundant marine species of calanoid copepods (Conover 1988; Hirche 1996; Atkinson 1998; Ohman et al. 1998; Varpe 2012) that are regarded central herbivorous links between lower (phytoplankton) and higher trophic level production. The non-productive part of the year is spent in the deep and safer parts of the ocean, away from the surface habitat where they feed. This diapause is spent as well-developed and near mature or mature stages, but with metabolism much reduced and fueled by reserves. Despite similar morphologies and overall life cycles, these copepod species span the full gradient from capital to income breeding (Miller et al. 1984; Conover 1988), and this diversity of capital and income breeding relates to phenology, annual routine, and life history variability (Varpe et al. 2009; Ejsmond et al. 2018). Our work is also relevant to arthropods more generally. Many insects in seasonal environments diapause in a mature or near mature stage (e.g. pupal stage in holometabolous insects), store reserves prior to diapause, and reproduce in spring shortly after diapause (Tauber et al. 1986; Hahn and Denlinger 2011). Examples include many butterflies (Lepidoptera), beetles (Coleoptera), stoneflies (Plecoptera) or mayflies (Ephemeroptera) (Lillehammer et al. 1989; Brittain 1990; Tammaru and Haukioja 1996; Morewood and Ring 1998; Walczynska et al. 2010; Haugen and Gotthard 2015). We ask: when should these organisms stop building reserves and instead prioritize survival by entering the safer diapause, and how should this timing depend on mortality risk?

We present a life history model designed for analyses of the risk-sensitivity of diapause timing and how this sensitivity depends on the positioning of the breeding strategy on a gradient from income to capital breeding. We expect the time used for storage to be particularly risk-sensitive in capital breeders. Our strategy gradient includes a mixed breeder category that can combine capital and income breeding, allowing us to also study how the degree of capital breeding is determined by risk. We analyze the sensitivity of the model predictions to seasonality in food availability, metabolic costs during diapause, stagedependent mortality, and seasonality in offspring value. A central point emerging from our work is that we must recognise the role storage plays in reproduction to make predictions about the timing of diapause in seasonal environments.

\section{The model}

\section{Life history and environment}

The model considers a short lived arthropod that is exposed to background mortality when it accumulates reserves. The model organism does not reproduce during its first growth and winter season (we refer to it as a juvenile during this period), but builds reserves and enters 
diapause before the winter and emerges ready for reproduction in spring (then referred to as adult). The model is well suited for organisms with diapause followed by reproduction, such as many copepods and other crustaceans, and to the many diapausing insects that build reserves prior to diapause and reproduce directly after or shortly after diapause. The model environment is seasonal, with the year lasting for $T_{y}=360$ days with two seasons, a summer and a winter with lengths $T_{S}$ and $T_{w}$ days, respectively (Fig. 1), set to 150 summer and 210 winter days in the examples presented below. During summer, juveniles feed and acquire resources and are exposed to the risk of death given by daily mortality rate $m_{a}$. The diapause state is characterized by daily mortality rate $m_{d}$. For the copepod life histories that in part inspire our work, the active phase is equivalent to feeding in the surface waters whereas entering diapause matches the migration to the deep-water refuge. A key assumption of our model is that diapause is a relatively safe state, in comparison to the feeding state, and we therefore assumed $m_{a}>m_{d}$ for all modelled scenarios. Staying active in summer allows juveniles to accumulate reserves, with potential pay-off through capital breeding in the following spring, but the longer in the feeding habitat the longer is the exposure to risk. This life-history trade-off between survival and time dedicated to acquire reserves

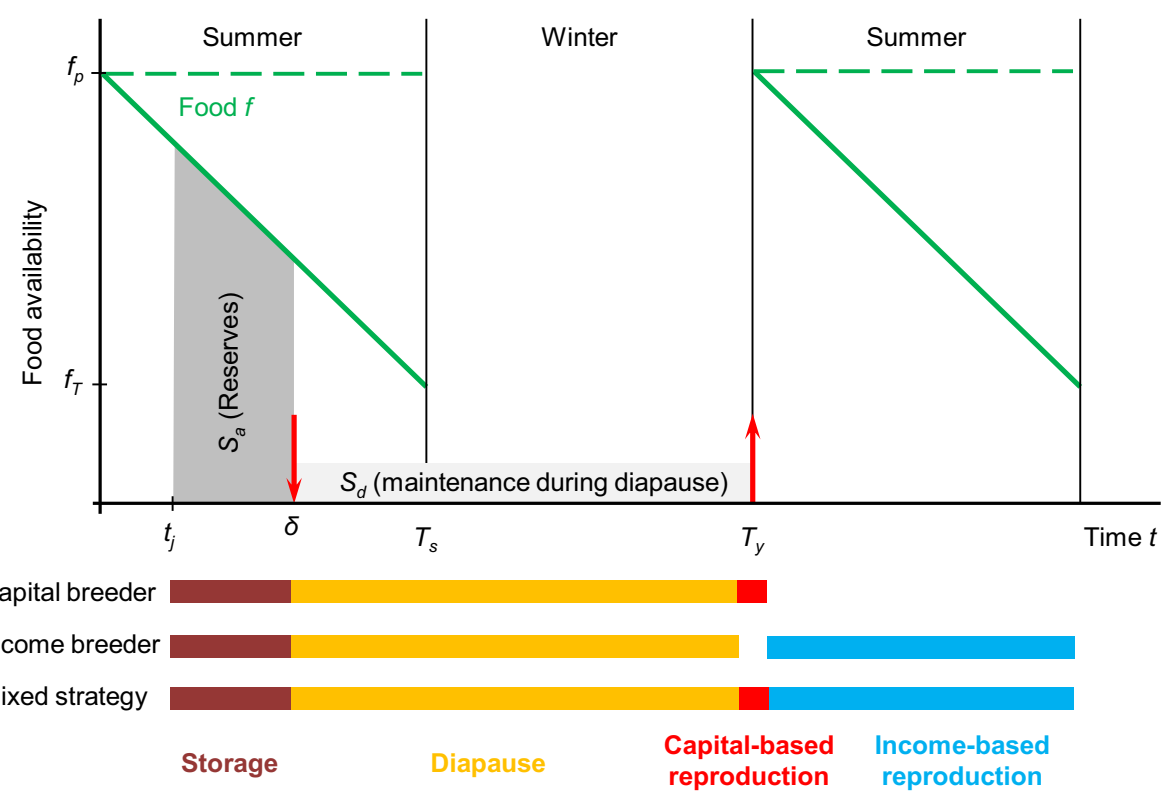

Fig. 1 The basic scheme of a seasonal life history model where the year, with duration of $T_{y}$ days, is divided into two seasons; food is available during $T_{s}$ summer days (green lines), and unavailable during winter. Food level at the beginning $f_{p}$ and end $f_{T}$ of the summer defines food availability. Two food scenarios are modelled (solid and broken green lines). The seasonally declining food availability may alternatively be thought of as seasonally declining food quality. The first point in time when development has reached a stage that allows for diapause is defined by $t_{j}$. The downward red arrow indicates the day when diapause starts $\delta$, which is optimized in order to maximize fitness, and the accompanying amount of reserves $S_{\text {a }}$ (depicted by the dark grey area). The upward red arrow represents the end of diapause. For the copepod case that we discuss, the arrows also represent seasonal migrations, to and from the deep-water diapause habitat. During diapause, organisms utilize reserves with $S_{d}$ being the reserves needed to cover maintenance costs during this period (the light gray area). For the three modelled life history strategies (capital breeder, income breeder, and mixed strategy), the periods for possible storage, diapause and reproduction are presented as horizontal color bars 
is a crucial element of the model. We keep the model general and easy to follow for a broad audience by assuming that subsequent cohorts of adults do not overlap and by excluding trade-offs with growth and feedback from the optimal strategy on the environment. Juvenile and adult mortality in our model is the same and equal to $m_{a}$ (but see analyses of stage-dependent mortality, Electonic supplementary material, Fig. S1), and we assume no seasonality in the value of newborn (but see analyses for scenarios with seasonally declining offspring value, Electronic supplementary material, Fig. S2).

The model seeks the day of diapause initiation $\delta$ (Fig. 1) that maximizes fitness. To account for complex development, with several larval stages in some arthropods, we assume that it takes $t_{j}$ days (Fig. 1), set to 30 days in the examples presented below, to develop from an egg at the beginning of the summer to a stage capable of accumulating reserves and subsequently diapause. It takes some time to build reserves, hence $\delta>t_{j}$ (Fig. 1). As we assume that all individuals, no matter breeding strategy, follow the same strategy until time $t_{j}$, we can omit this first part of the life cycle from further consideration.

Physiological processes in the model are kept general and not parameterized for a particular species, and rates of food gain, metabolism and maintenance costs are kept relative to each other. This simplicity allows the model to be general enough to cover a broad range of life histories. The dynamics of food availability $f(t)$, defining rate of energy assimilation (e.g. joule per unit of time), (Eq. 1) is assumed linear. In case of a marine environment, $f(t)$ is a simplified and flexible representation of a population of primary producing algae during the year, and can be given by:

$$
f(t)=-\frac{f_{p}-f_{T}}{T_{S}} t+f_{p}
$$

Food availability depends on food level at the beginning and end of the summer, $f_{p}$ and $f_{T}$ respectively (Fig. 1). By manipulating $f_{T}$ we modeled different scenarios including a constant food gain when $f_{p}=f_{T}$ (see Fig. 1).

The modeled arthropod converts acquired food to reserves and covers maintenance costs $C_{m}$ (Eq. 2) where $\tau$ is a time index equal to 0 at $t_{j}$.

$$
\frac{d S}{d \tau}=f(\tau)-C_{m}
$$

By solving Eq. 2 we get the amount of reserves $S_{a}$, at the time of diapause initiation $\delta$ (see Eq. 3).

$$
S_{a}=\left(\delta-t_{j}\right)\left(\frac{f\left(t_{j}\right)+f(\delta)}{2}-C_{m}\right)
$$

There is no upper limit to the amount of reserves, but we do not consider strategies where individuals spend the winter in an active state. Hence, the time available for feeding during summer determines the maximal level of reserves.

We assume that there are no costs of entering diapause and during diapause reserves are used for metabolism at a rate given by

$$
\frac{d S}{d \tau}=-x C_{m}
$$

where $x$ is a coefficient that expresses the maintenance costs during diapause relative to the costs when in the active phase. Estimates of relative magnitude of maintenance costs in arthropods are taxon or even species specific. In marine copepods, the metabolic rate may 
be as much as 10 times lower during diapause than during the active phase (Pasternak et al. 1994), which corresponds to $x=0.1$ in our model. For the copepod Calanus glacialis these costs are around 6-3 times lower (Morata and Søreide 2015), hence $x$ between 0.17 and 0.33 . To keep our model general we consider $x$ ranging from 0 (no reserves used during diapause) to 1 (same maintenance cost during active and diapause phase).

All individuals, no matter diapause initiation strategy, mature and emerge from diapause at the beginning of the next summer (Fig. 1) and are then ready to produce eggs. This can be kept simple as our focus is the onset of diapause.

The energetic value of the reserves necessary to cover maintenance costs during diapause $S_{d}$ is equal to

$$
S_{d}=-\left(T_{Y}-\delta\right) x C_{m}
$$

and the reserves available after diapause are the outcome of the balance between net assimilation in summer and reserves used to cover metabolic processes during diapause i.e. $S_{a}+S_{d}$ (note that $S_{d}$ is a negative number, Eq. 5). We assumed that when reserves were insufficient to cover metabolic costs during diapause i.e. from $\delta$ to the beginning of the next summer, the organism dies during diapause.

\section{Breeding strategies and mortality rate}

In our model we consider three types of breeding strategies: (1) pure capital breeding, i.e. egg production covered by reserves obtained during the previous year; (2) income breeding, i.e. egg production covered by current food intake; and (3) a mixed strategy, which is a combination of capital and income breeding (Fig. 1). We assumed that capital breeders die after reserves are emptied and that income and mixed breeders die before their second winter (cf. Varpe 2012).

The optimal strategy maximizes expected reproductive success, a measure related to the amount of reserves (see Eq. 3), and the risk taken while in the active versus the diapause state. Survival of the period from time $t_{j}$ (Fig. 1) to the beginning of summer is with probability $p$ given by

$$
p(\delta)=\exp \left[-m_{a}\left(\delta-t_{j}\right)-m_{d}\left(T_{y}-\delta\right)\right]
$$

where $m_{a}$ and $m_{d}$ are mortality rates during the active phase and diapause, respectively.

We test our model for a broad range of mortality rates. Estimation of death rates in marine arthropods can be difficult due to advection of water masses and the large spatial scales often involved. For copepods, daily survival rates range from close to 0 and up to $20 \%$ of the individuals dying (e.g. Aksnes and Ohman 1996; Gentleman et al. 2012), representing life expectancies from around 2 weeks to several years. Consequently, we tested a range of mortality rates $m_{a} \in\langle 0.005,0.035\rangle$ for the feeding habitat, broad enough to cover observed variability of adult and juvenile life expectancies in a range of arthropods (e.g. Walczyńska 2010; Remmel et al. 2011; Vogt 2012). Assumed mortality rates represent environments in which the expected proportion of individuals surviving a 3-month period in their active phase falls between 64 and 4\%. Importantly, for the wide range of $m_{a}$ considered and assuming that $m_{a}>m_{d}$, our results were not affected qualitatively by the level of mortality rates $m_{d}$ during diapause. Hence, we did not parameterize mortality during diapause, but assumed $m_{d}=0.004$, corresponding to $30 \%$ of the individuals dying if a population diapauses for 3 months. 


\section{Income, capital and mixed strategy of breeding}

We measure egg production as energetic units allocated to reproduction.

Capital breeder The expected egg production for a pure capital breeder $V_{C}$ equals the energetic value of reserves at the first day of the summer, i.e. the day when eggs are released multiplied by the probability of surviving to this day (Fig. 1), and given by

$$
V_{C}=p(\delta)\left(S_{a}+S_{d}\right)=p(\delta) R_{C}
$$

where $R_{C}$ is allocation to reproduction by a pure capital breeder and $p(\delta)$ the probability to survive the winter.

Income breeder An income breeder cannot use reserves for reproduction, but will produce eggs if there is food available. We assume it to produce eggs continuously (Fig. 1). The expected number of produced eggs for an income breeder that survived the winter $R_{I}$, is given by

$$
R_{I}=\int_{t=0}^{T_{S}} \exp \left(-m_{a} t\right)\left(f(t)-C_{m}\right) d t
$$

(for the solution of Eq. 8 see Supplementary material). The fitness of the income breeder $V_{I}$ depends on day of diapause initiation $\delta$ and the probability of survival to the end of winter, and is given by

$$
V_{I}=p(\delta) R_{I}
$$

Mixed capital and income An organism with a mixed strategy first breeds as a capital breeder and then as an income breeder (Fig. 1). The expected egg production for the mixed strategy $V_{M}$ is the sum of the expected income and capital breeding strategies.

$$
V_{M}=p(\delta)\left(R_{C}+R_{I}\right)
$$

Note that the timing of diapause of the mixed breeder determines its breeding strategy through the amount of reserves gathered, and thereby position it along the income to capital breeder continuum. Depending on the selection pressures, the optimality considerations can therefore result in mixed-breeders positioned anywhere from an income breeder to a pure capital breeder with large reserves.

Optimization For each of the three strategies we calculate the optimal onset of diapause $\delta$ that maximizes fitness, by solving the condition in which the derivative of the expected reproductive success equals zero (Supplementary material). Note that the rate of resource assimilation during the active phase only depends on food availability $f(t)$ and maintenance $\operatorname{costs} C_{m}$. Consequently, our results are general and depend on the relative amount of food needed to cover maintenance costs.

\section{Relaxing two of the model assumptions}

We add additional analyses of two of our assumptions. (1) We analyze how sensitive the model predictions are to differences in summer-season mortality rate $m_{a}$ for individuals in juvenile (e.g. prior to diapause, see Eq. 6) versus the adult stage (i.e. after diapause, see Eq. 8). This analysis of stage-dependent mortality is particularly motivated by the different life forms and therefore sometimes different mortality rates of holometaboleous insects. (2) 
We relax our baseline assumption of birth-time independent offspring value. Other lines of our work have highlighted that offspring produced at different times of the season have unequal future prospects (Ejsmond et al. 2010), for instance to decline as the season progresses (Varpe et al. 2007). We therefore add a scenario of seasonally declining offspring value (cf. methodology in Ejsmond et al. 2010). Both of these model modifications, including their results, are presented in the Supplementary material, but discussed below.

\section{Results}

\section{Baseline model, with constant food and no maintenance costs during diapause}

When food is constant over the summer season, $f(t)=f_{p}$, and the costs of maintenance during diapause are negligible $x=0$, the optimal diapause strategy for the three strategies differs and are given by conditions 11 to 12 . Subscripts $I, C$ and $M$ refer to the income, capital and mixed breeder strategy, respectively (see Electronic supplementary material for calculations). Diapause strategies that maximize fitness (Eqs. 11-13) are presented in two ways, by time in the season $\delta$ or level of reserves $\gamma$ (given in the parentheses)

$$
\begin{gathered}
\delta_{I}=t_{j}, \quad\left(\gamma_{I}=0\right) \\
\delta_{C}=t_{j}+\frac{1}{m_{a}-m_{d}}, \quad\left(\gamma_{C}=\frac{f_{p}-C_{m}}{m_{a}-m_{d}}\right) \\
\delta_{M}=\delta_{C}-\frac{R_{I}}{f_{p}-C_{m}}, \quad\left(\gamma_{M}=\gamma_{C}-R_{I}\right)
\end{gathered}
$$

In the baseline model we assumed that costs of maintenance during diapause are irrelevant and the income breeder gets no pay-off from reserves that remain at the end of winter. An income breeder should therefore enter diapause immediately after reaching the developmental stage that allows for diapause (Eq. 11, Fig. 2). Importantly, this decision is independent of the mortality risk and rate of energy assimilation. For a pure capital breeder, on the other hand, the day of entering diapause $\delta$, as well as amount of reserves $\gamma$, is inversely related to the rate of mortality in the feeding habitat $m_{a}$ (Eq. 12, Fig. 2) i.e. the higher the mortality the earlier diapause and less reserves are gathered. The capital breeder maximizes expected amount of reserves available for egg production next year, where this expectation takes into account the risk of death during the feeding phase when reserves are accumulated. Because we express reserves in the same energetic units as assimilated food, $\gamma_{C}$ also scales with energy assimilation (Eq. 12, Fig. 2). Finally, for the mixed strategy, diapause initiation takes place for reserve levels that fall between $\gamma_{I}$ and $\gamma_{C}$, and the difference in optimal diapause threshold for a mixed breeder $\gamma_{M}$ and capital breeder $\gamma_{C}$ is proportional to the benefit from income breeding $R_{I}$ (see Eq. 8). The optimal reproductive strategy by the mixed breeder, $\delta_{M}$ and $\gamma_{M}$ (Eq. 13), shows that both high mortality $m_{a}$ when reserves are accumulated and high rate of reproduction from incoming resources $R_{I}$ select against capital breeding. 


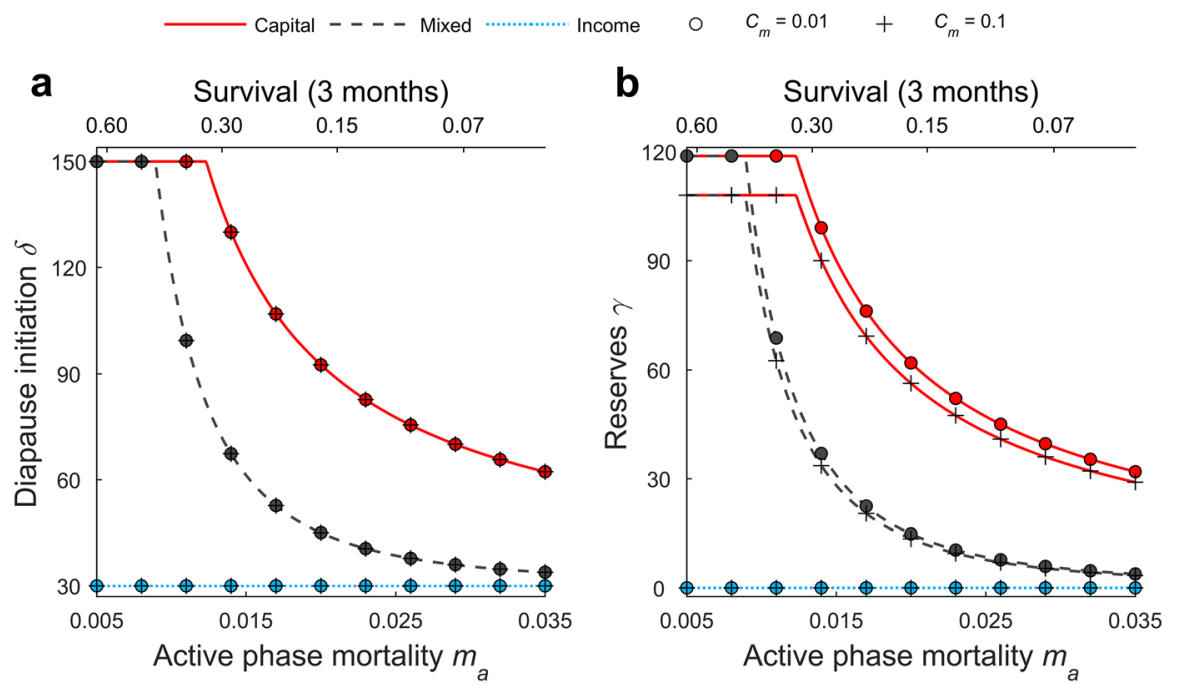

Fig. 2 Baseline model. The day of diapause initiation $\delta$ (a) and the optimal level of reserves $\gamma(\mathbf{b})$ presented for a gradient of mortality $m_{a}$ during the active phase of the year, for the capital, mixed and income breeding strategies. Metabolic costs in the active phase $C_{m}$ are given in the legend and can be interpreted as a proportion of daily consumption rate. Diapause initiation was calculated under the assumption that costs of metabolism during diapause are negligible (relative cost of maintenance during diapause $x=0$ ) and for constant food during the summer $\left(f_{p}=f_{T}\right)$. Note the plateau in $\gamma$ and $\delta$ for low mortality rates $m_{a}$ caused by storage taking place to the end of the feeding season, hence $\delta=T_{s}$. Because costs of maintenance are negligible during winter, income breeders initiate diapause immediately after reaching $t_{j}$ i.e. the first stage allowed to diapause

\section{Model with metabolic costs during diapause}

The baseline model did not take into account that reserves are used during diapause. The amount of reserves needed for maintenance during diapause determines the minimal value of $\gamma$ and time spent in the active phase, set by $\delta$. Hence, for an income breeder, the level of reserves increases with costs of maintenance during diapause but is constant across different mortality risks $m_{a}$ (see the black surface in Fig. 3). Capital and mixed breeders store more than is needed for diapause (Fig. 3). Their breeding strategies are risk sensitive under both low (Fig. 3a) and high (Fig. 3b) costs of maintenance during diapause. When mortality during the active phase increases, they start the diapause earlier and with smaller reserves (Fig. 3). Under low mortality, capital and mixed breeders stay active as long as possible i.e. to the last day of summer, gathering maximal amounts of reserves (note flat planes in Fig. 3a, b).

\section{Model with dynamic food}

For our analyses we also add seasonality in food availability. We set food consumption at the end of the season lower than at the beginning, i.e. $f_{T}<f_{p}$, and equal to the metabolic $\operatorname{costs} C_{m}$, which means that the energy balance will turn negative on the first day of winter. The risk sensitivity of the predicted diapause strategies is not affected by the assumed 


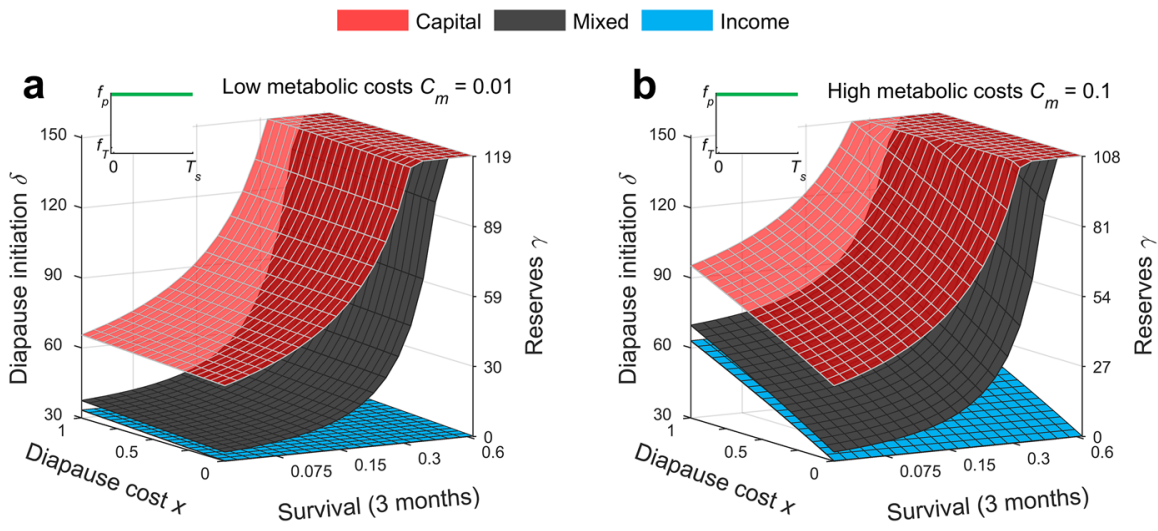

Fig. 3 Constant food scenario. Optimal diapause timing $\delta$ and level of reserves $\gamma$ for an income breeder (blue surface), pure capital breeder (transparent red surface) and mixed breeder (gray surface) when food intake $\left(f_{p}=f_{T}\right)$ is constant during summer (see inserts), for low metabolic costs during the active phase $C_{m}=0.01$ (a) and for high such costs $C_{m}=0.1$ (b). The blue surface also represents the critical reserves necessary to survive the winter. Note that when relative cost of maintenance during diapause $x=0$, i.e. no reserves used during diapause, income breeders migrate with no reserves $\gamma_{I}=0$ at day $\delta_{I}=t_{j}$ i.e. as early as possible. The critical amount of reserves increases with the coefficient $x$ scaling the maintenance costs during diapause (Eq. 4.)

seasonality in food, regardless of reproductive strategy, and the degree of capital breeding is highest in the safest environments (Figs. 3a, b versus $4 \mathrm{a}, \mathrm{b}$ ). With decreasing food during summer, the model organisms need more time to store for diapause. Capital and mixed

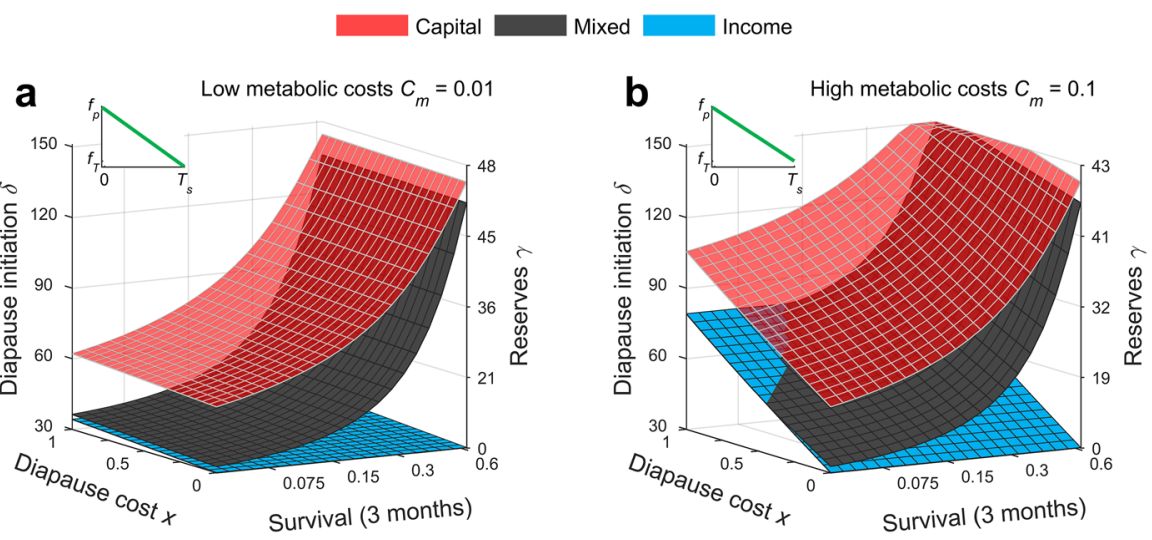

Fig. 4 Seasonally declining food scenario. Optimal timing $\delta$ and level of reserves $\gamma$ for an income breeder (blue surface), pure capital breeder (transparent red surface) and mixed breeder (gray surface) considered under seasonally decreasing food availability (see inserts), and under low metabolic costs during the active phase $C_{m}=0.01$ (a) and high such costs $C_{m}=0.1$ (b). Food availability at the end of the summer was set to $f_{T}=C_{m}$. Note that the blue surface also represents the critical reserves necessary to survive the winter, which increases with a coefficient $x$ scaling the maintenance costs during diapause (Eq. 4). The reserves $\gamma$ do not increase proportionally with day of diapause initiation $\delta$ (note the nonlinear scale of the reserves axis) because the rate of food intake declines as the summer season progresses. For legibility in panel b, the gray surface indicating $\delta$ and $\gamma$ for the mixed breeder was removed when identical with the income breeder strategy 
breeders store less than under constant food availability (Figs. 3a, b versus 4a, b). When the food conditions deteriorate during the feeding season and the maintenance costs of diapause are low, capital and mixed breeders diapause earlier than under constant food availability (Fig. 5a, b). High mortality risk forces them to diapause early, and when maintenance costs are high they may need to stay for longer than under constant food to gather reserves needed to survive to reproduction (Fig. 5c, d). Mixed breeders consequently behave as income breeders when the risk while feeding and costs of diapause are high (Fig. 4b).

\section{Discussion}

We study diapause timing as a key seasonal event, a transition from a risky feeding mode to a safer and less energy demanding non-feeding mode. Our analyses link phenology and breeding strategies through a fitness perspective on the consequences of storage prior to diapause. The model predictions suggest that mortality risk is an important driver of diapause timing and the capital component of reproduction. Mixed breeders, and pure capital breeders in particular, respond to elevated risk by entering diapause earlier and with less reserves. These results largely remain when mortality risk is allowed to be stage-dependent.

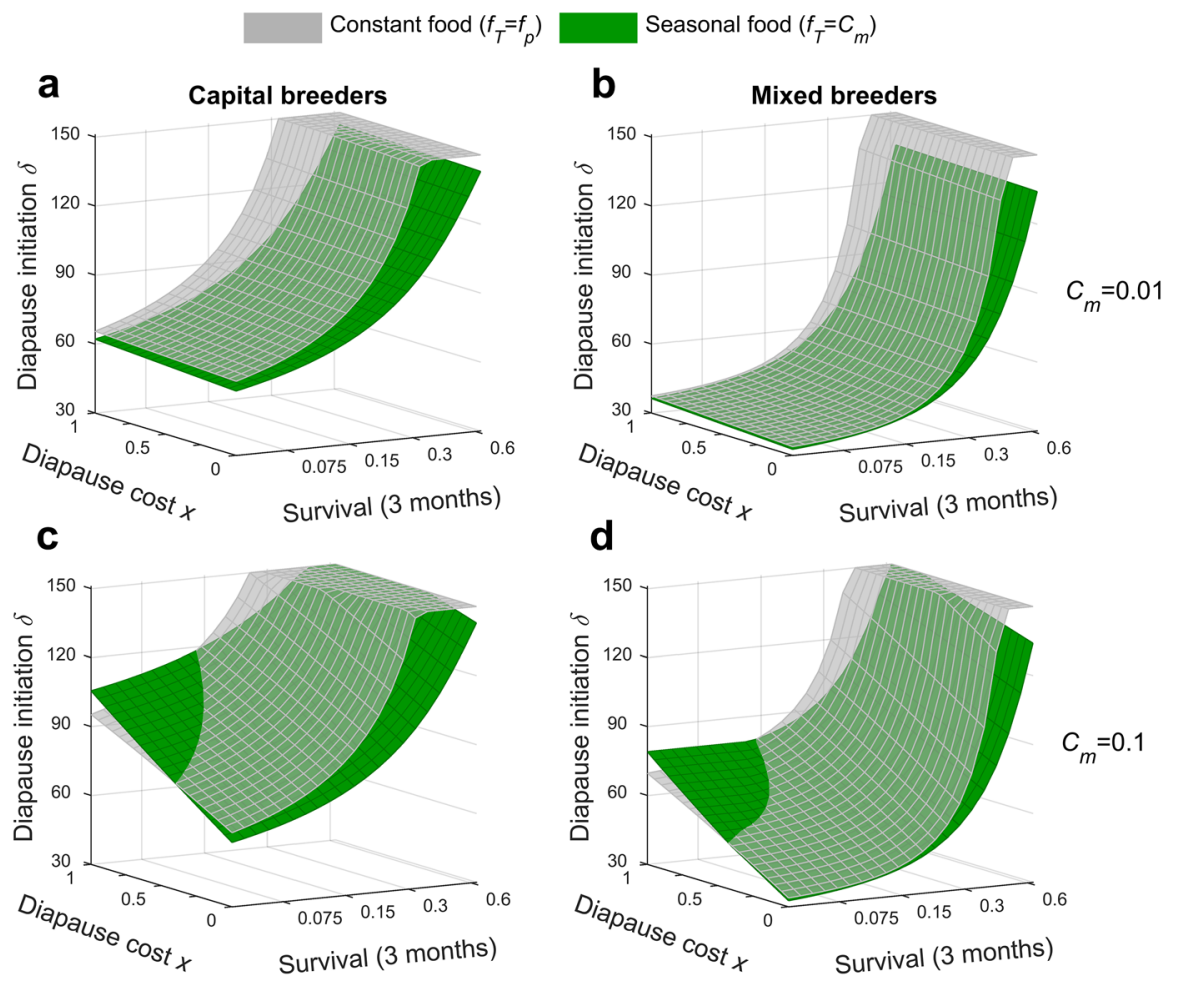

Fig. 5 Comparisons of the constant and seasonally declining food scenarios. Optimal timing of diapause $\delta$ for a capital $(\mathbf{a}, \mathbf{c})$ and mixed breeder $(\mathbf{b}, \mathbf{d})$ considered under constant (transparent surface) and seasonally decreasing food availability (filled green surface), and under low $C_{m}=0.01(\mathbf{a}, \mathbf{b})$ and high $C_{m}=0.1(\mathbf{c}, \mathbf{d})$ metabolic costs during the active phase 
However, when mortality risk is high and adults survive better than juveniles, then diapause timing in mixed breeders moves towards that of income breeders (Fig. S1). This change occurs because fitness gains from income breeding pay off relatively more than continued storage prior to diapause. Furthermore, including seasonally declining offspring value does not affect our general conclusions, but mixed breeders shift towards capital breeding when offspring produced late contribute poorly to fitness (Fig. S2).

Based on our predictions, we argue that the role of predators in shaping diapause phenology and breeding strategy in arthropods should be highlighted. Specifically, predation risk should be listed among other drivers of diapause timing in capital breeders such as feeding season length (Sainmont et al. 2014), food supply (Walczynska et al. 2010) and birth-time dependent offspring prospects (Varpe et al. 2007). The trade-off between storage and survival that we have modelled is not limited to short lived invertebrates. We expect similar selective forces for the timing of dormancy, amount of gathered reserves, and degree of capital breeding in longer lived organisms for instance fish, reptiles, and mammals (Reznick and Braun 1987; Atkinson and Ramsay 1995; Bonnet et al. 2002; McBride et al. 2015). However, understanding how the trade-off between storage and survival impacts diapause (or migration) phenology in longer-lived species require additional lifehistory trade-offs, for instance relating to body size, indeterminate growth and iteroparity (Houston et al. 2007; Stephens et al. 2014; Ejsmond et al. 2015; Varpe 2017).

\section{Risk-sensitive life histories and the trade-offs involved}

Capital breeding comes with survival costs due to predation risk when reserves are gathered, a pre-breeding cost of reproduction (Jönsson 1997). Our study broadens this perspective and explores changes in phenology and life-history of capital breeders driven by the level of mortality risk. The model predicts strong selection for timing of diapause in organisms that optimize the time dedicated for foraging in response to experienced risk. For those who store for reproduction, such optimization should lead to large reserves (and much time spent feeding) when predation risk is low and smaller reserves (and less time) when the risk is high. Consequently, the trade-off between storage and survival influences both individual state (body condition) and phenology. In pure income breeders, only a minimum and fixed threshold level of reserves should be obtained in order to survive the winter, given that winter costs and duration is predictable. In life history theory, storage is often considered a reservoir preventing from death in fluctuating environments (Fischer et al. 2011) or during long unproductive seasons of variable duration (Giacomini and Shuter 2013). Capital breeding complicates this perspective as building up long-term reserves for reproduction generates a multitude of life history trade-offs in particular with growth (Reznick and Braun 1987; Jørgensen et al. 2006; Ejsmond et al. 2015). The predicted trade-off between survival and storage is in principle synonymous with the well-established life-history theory of optimal growth rate mediated by foraging rate (Werner and Anholt 1993; Anholt and Werner 1995). This theory, founded on the premise that foraging is risky, predicts that organisms maximize fitness by adjusting the growth rate and risk taken while foraging i.e. they trade off growth rate with survival (see also Kozłowski 2006). One of the ultimate drivers for growth is that larger size means higher fecundity and so growth is a long-term investment in future reproduction (Williams 1966; Ejsmond et al. 2010). Preparation for capital breeding is similar to growth by being an investment in future reproduction, hence 
forms part of the residual reproductive value (Williams 1966; Ejsmond et al. 2015). Similarly to risk-driven optimization of growth rate, capital breeders exposed to high risk compromise feeding and the amount of reserves obtained.

\section{Mortality as a driver of diapause phenology in capital breeders}

We find that the more a strategy depends on capital breeding, the more risk-sensitive are timing and storage decisions. Testable predictions emerge. The amount of reserves built by capital breeders should be sensitive to variability in risk, and capital breeders should store less when the risk is high, and thereby sacrifice reproduction. Furthermore, consistently high mortality rate during the productive season selects for reproductive strategies more toward income breeding. The conclusions about risk-dependent storage and timing of diapause are particularly relevant for several arthropod groups.

Many insects change their behavior in response to increased mortality risk. Females of the leaf feeding two-spotted spider mite (Tetranychus urticae) lower their metabolic rate, abandon the leaf environment and migrate to winter diapause refuges (i.e. bark crevices and soil litter) when exposed to volatile predator-associated cues or predator presence (Kroon et al. 2004, 2008). The longer the diapause duration the lower the rate of oviposition, peak rate of oviposition, and total egg production, which suggests a significant capital component of reproductive investment in these mites (Kroon and Veenendaal 1998).

All mayflies (Ephemeroptera) and many species of stoneflies (Plecoptera) are pure capital breeders with juveniles storing all the resources that later fuel reproduction (Lillehammer et al. 1989; Brittain 1990). The reproducing adults do not feed. In line with our model predictions, juveniles of these freshwater insects develop faster, and molt to the adult stage at a smaller size, when exposed to predators, which increases the survival probability at the expense of fecundity (Dahl and Peckarsky 2003). Risk-dependent duration of the juvenile period in turn drives differences in the phenology of metamorphosis as found when comparing timing and size at emergence in streams and lakes with and without predatory fish (Peckarsky et al. 2001). The variability in timing of emergence in mayflies is caused by the same trade-off between survival and time spent building reserves as described for the pure capital breeder strategy in our model. In sum, predators may act as an important determinant of metamorphosis phenology in the above examples.

Among Lepidoptera, different families represent the full continuum of strategies from income to capital breeding (Tammaru and Haukioja 1996) with some evidence for degree of capital being dependent on predation risk. In several moth species, larvae that are exposed to lower bird predation early in the season, reach larger pupal size than later larvae (Teder et al. 2010), which likely means more reserves that can be used for reproduction (Liu et al. 2007). In the Geometridae family, moths well-known for their use of reserves for reproduction, the degree of capital breeding is associated with several morphological traits as well as the lifestyle of adults (Davis et al. 2016). Our model adds the possibility that some of this diversity is caused by differences in mortality risk prior to diapause. Furthermore, in these moths, the degree of capital breeding and timing of storage for reproduction has been hypothesized to depend on the relation between the abundance of oviposition targets and the abundance of food for adults (Javoiš et al. 2011). An alternative prediction from our model would be that mortality differs between habitats, which would lead to variability in the duration of the juvenile period, amount of reserves, and degree of capital breeding. 


\section{Drivers of diapause and migration timing: the copepod case}

Our work is in part inspired by a long debate about the cues of diapause and the drivers of life history diversity in a key group of ocean herbivores, the calanoid copepods. Representatives of seasonal migrants with a diapause-like overwintering stage include the Calanus spp species of the Atlantic and Neocalanus spp in the Pacific Ocean (Conover 1988), Calanoides acutus in the Southern Ocean (Atkinson 1998), but also lower-latitude species with strong elements of storage and deep-water dormancy (Ohman et al. 1998). These copepods span the full range from income to pure capital breeding species. Some Neocalanus spp. are pure capital breeders unable to feed in their adult stage (Miller et al. 1984). Calanus hyperboreus can also be regarded a capital breeder (Hirche 2013), but it is iteroparous in contrast to the semelparous Neocalanus spp (see also Varpe and Ejsmond 2018). Others, such as C. glacialis or C. acutus, adopt a mixed strategy where the same individual may perform capital breeding early in the season followed by income breeding during the bloom (Hirche and Kattner 1993; Hagen and Schnack-Schiel 1996; Daase et al. 2013). Yet others, such as Calanus finmarchicus or C. helgolandicus, are predominantly income breeders (Bonnet et al. 2005), although a slight component of capital breeding is sometimes suggested for $C$. finmarchicus (Rey-Rassat et al. 2002). Following our model predictions, their positon on the capital to income breeder continuum should impact how copepods respond to risk during the storage period, and thereby determine the timing of their seasonal migrations.

There is much interest, but so far few clear answers, as to what governs the timing of seasonal migrations, and thereby diapause, in copepods. Several suggestions have been made about drivers of diapause initiation, including food availability (Hind et al. 2000), predation risk (Kaartvedt 2000), temperature (Niehoff and Hirche 2005), environmental stochasticity (Fiksen 2000), or combinations of these. A mechanism that has received considerable attention is the role of lipid reserves and the prediction that copepods migrate and enter diapause as soon as they have stored sufficient reserves to fuel them through the winter (Johnson et al. 2008; Maps et al. 2010), incorporated into models as a fixed ratio of lipids to body mass. Our work is consistent with this prediction only for income breeders, such as the much studied Calanus finmarchicus or C. helgolandicus. The logic of a fixed reserve does not work when capital breeding forms part of the reproductive strategy. Instead, capital breeders should be impacted by the risk of obtaining the reserves and also by the relative survival probability in the feeding- versus the diapause-habitat. There are few empirical tests of how long individuals should keep storing, and how much they should store (but see Hays et al. 2001; Schmid et al. 2018); this despite the well-defined oil sac of these copepods and the ease with which individual body condition therefore can be measured (Vogedes et al. 2010). Further studies are also needed of the complex interactions between the short-term predator avoidance offered by diel vertical migrations and the longer term seasonal migrations (Bandara et al. 2018).

Should the risk-driven timing of diapause in capital breeders be regarded a fixed strategy produced by contemporary evolution (cf. Peijnenburg and Goetze 2013) or a strategy with plasticity and the ability to respond to cues about mortality risk? Organisms unable to perceive reliable cues about mortality risk are more likely to evolve fixed routines or bet-hedging strategies (Ji 2011), which through a fluctuating selection regime could even maintain genetic variation in genes responsible for diapause timing. Plastic responses on the other hand demand predator-derived cues to be a reliable signal, and there are indeed several proximate mechanisms responsible for risk-sensitive behavior in zooplankton. Predator-derived kairomones trigger diverse morphological, behavioral and life-history 
responses in freshwater and marine zooplankton (reviewed by Lass and Spaak 2003), such as transition to diapause in daphnids (Slusarczyk et al. 2013). The role of chemical cues as a reliable source of information is often doubted in marine environments with strong advection. But marine copepods have predator induced responses, such as reduced feeding activity (Cieri and Stearns 1999) or altered development and growth (Bjærke et al. 2014) in response to predator-derived chemicals, or increased diel vertical migration (Bollens and Frost 1989) and even reversed diel vertical migration (Ohman et al. 1983). Mechanical and visual stimuli, as for instance predator encounter, may also induce risk-sensitive behavioral reactions (Bollens et al. 1994). In sum, there are multiple studies of copepods showing escape related activities when exposed to predators. These are all examples of the ecology of fear (Brown and Kotler 2004), a concept referring to the strong effects of predator cues and signals on prey behavior.

Our model predictions translate to hypotheses that can be tested in field or laboratory studies. (1) Because predation risk can outweigh the fitness gains of larger reserves, we predict there to be situations when there is plentiful food available but where individuals from capital breeding species nevertheless descend before the end of the feeding season and with less than full reserves. (2) We expect capital breeders to be most successful in areas with relatively low predation risk, and particularly when predation risk is low during the later parts of the bloom when reserves are accumulated. Few studies so far include such top-down perspectives when discussing large scale patterns of copepod life history strategies, but see (Kaartvedt 2000; Varpe et al. 2015). Finally, a potential corollary of our predictions is that capital breeders, because of their pre-breeding costs of reproduction, have more to gain from adjusting to predation risk and therefore have evolved a more elaborated repertoire of detecting and responding to variability in risk.

\section{Concluding remarks}

There are many ecological consequences of the predicted risk-sensitivity, such as carryover effects onto the timing of diapause emergence in spring, which also may depend on reserves (Varpe et al. 2009; Williams et al. 2017). There would also be population dynamical consequences, as an increase in predator numbers would impact the level of reserves and therefore fecundity of capital breeders. Such top-down regulation would also impact meta-ecosystem processes; for instance the lipid (and therefore carbon) flow between the surface habitat and the deep oceans (Jónasdóttir et al. 2015), caused by deep water diapause in copepods.

Income and capital breeding arthropods are diverse with respect to life history traits and multiple trade-offs should ideally be modelled. That would however make it more difficult to explain the specific trade-off between storage and survival focused on here. As an example of trade-off complexity, generation time, structural size and degree of capital breeding are related in arthropods through trade-offs between growth, reproduction and storage. In recent work, we found that large capital breeders perform best under low mortality risk and short feeding seasons, and when more is allocated to structural size then less is allocated to reserves (Ejsmond et al. 2018). Long feeding seasons and high mortality select for early maturation because instead of growing larger, it is optimal to place multiple generations within one feeding season (Roff 1980; Ejsmond et al. 2018).

Our analyses excluded explicit proximate mechanisms shaping seasonal reproductive tactics as this would compromise generality and is less important from the point of the presented fitness considerations. We also did not consider stochasticity in the amount of 
reserves needed to survive the winter. These simplifications allowed us to keep our work didactic and focused on the core risk-related trade-off operating along the income to capital breeder gradient. An important aim for us is to stimulate research on risk sensitivity of capital breeding. Empirical work could show to what extent phenotypic plasticity in diapause timing can mediate responses to risk exposure and the degree of capital breeding. Our arthropod examples only offer indirect evidence as they either investigate risk exposure or degree of capital breeding, but not both of them in parallel. For future model developments we find it particularly promising to open up for environmental stochasticity in the amount of reserves needed for diapause and variation in mortality risk between years. The later aspect is tightly linked to whether organisms are able to perceive and forecast predation risk.

At the general life history level, our model represents a clear case of how the trade-off between storage and survival impacts the evolution of diapause timing. Large diversity in the adaptive value of reserves across taxa leads to variability in diapause strategies and timing. The position of a life history on the income to capital breeding gradient is one such source of variability and should be taken into account, or perhaps even taken as a starting point, for studies of diapause phenology.

Acknowledgements This work was supported by a Grant from the National Science Centre in Poland for Project No. 2014/15/B/NZ8/00236 and Jagiellonian University funds (DS/WB/INoS 757/18). ØV also thanks the Fulbright Arctic Initiative for funding. We thank Toomas Tammaru and an anonymous reviewer for very helpful comments on an earlier version of the article.

\section{Compliance with ethical standards}

Conflict of Interest The authors declare no conflict of interest.

Open Access This article is distributed under the terms of the Creative Commons Attribution 4.0 International License (http://creativecommons.org/licenses/by/4.0/), which permits unrestricted use, distribution, and reproduction in any medium, provided you give appropriate credit to the original author(s) and the source, provide a link to the Creative Commons license, and indicate if changes were made.

\section{References}

Aksnes DL, Ohman MD (1996) A vertical life table approach to zooplankton mortality estimation. Limnol Oceanogr 41:1461-1469

Anholt BR, Werner EE (1995) Interaction between food availabiltiy and predation mortality mediated by adaptive behavior. Ecology 76:2230-2234

Atkinson A (1998) Life cycle strategies of epipelagic copepods in the Southern Ocean. J Mar Syst 15:289-311

Atkinson SN, Ramsay MA (1995) The effects of prolonged fasting of the body-composition and reproductive success of female polar bears (Ursus maritimus). Funct Ecol 9:559-567

Bandara K, Varpe Ø, Ji R, Eiane K (2018) A high-resolution modeling study on diel and seasonal vertical migrations of high-latitude copepods. Ecol Model 368:357-376

Bjærke O, Andersen T, Titelman J (2014) Predator chemical cues increase growth and alter development in nauplii of a marine copepod. Mar Ecol Prog Ser 510:15-24

Bollens SM, Frost BW (1989) Predator-induced diel vertical migration in a planktonic copepod. J Plankton Res 11:1047-1065

Bollens SM, Frost BW, Cordell JR (1994) Chemical, mechanical and visual cues in the vertical migration behavior of the marine planktonic copepod Acartia hudsonica. J Plankton Res 16:555-564

Bonnet X, Lourdais O, Shine R, Naulleau G (2002) Reproduction in a typical capital breeder: costs, currencies, and complications in the aspic viper. Ecology 83:2124-2135 
Bonnet D, Richardson A, Harris R et al (2005) An overview of Calanus helgolandicus ecology in European waters. Prog Oceanogr 65:1-53

Brittain JE (1990) Life history strategies in Ephemeroptera and Plecoptera. In: Mayflies and stoneflies: life histories and biology. Springer, Berlin, pp 1-12

Brown JS, Kotler BP (2004) Hazardous duty pay and the foraging cost of predation. Ecol Lett 7:999-1014

Cieri MD, Stearns DE (1999) Reduction of grazing activity of two estuarine copepods in response to the exudate of a visual predator. Mar Ecol Prog Ser 177:157-163

Cohen D (1970) A theoretical model for optimal timing of diapause. Am Nat 104:389-400

Conover RJ (1988) Comparative life histories in the genera Calanus and Neocalanus in high-latitudes of the northern hemisphere. Hydrobiologia 167:127-142

Daase M, Falk-Petersen S, Varpe $\varnothing$ et al (2013) Timing of reproductive events in the marine copepod Calanus glacialis: a pan-Arctic perspective. Can J Fish Aquat Sci 70:871-884

Dahl J, Peckarsky BL (2003) Developmental responses to predation risk in morphologically defended mayflies. Oecologia 137:188-194

Davis RB, Javois J, Kaasik A et al (2016) An ordination of life histories using morphological proxies: capital vs. income breeding in insects. Ecology 97:2112-2124

Drent RH, Daan S (1980) The prudent parent: energetic adjustments in avian breeding. Ardea 68:225-252

Ejsmond MJ, Czarnoleski M, Kapustka F, Kozlowski J (2010) How to time growth and reproduction during the vegetative season: an evolutionary choice for indeterminate growers in seasonal environments. Am Nat 175:551-563

Ejsmond MJ, Varpe $\varnothing$, Czarnoleski M, Kozlowski J (2015) Seasonality in offspring value and trade-offs with growth explain capital breeding. Am Nat 186:E111-E125

Ejsmond MJ, McNamara JM, Søreide J, Varpe $\varnothing$ (2018) Gradients of season length and mortality risk cause shifts in body size, reserves and reproductive strategies of determinate growers. Funct Ecol 32:2395-2406

Fiksen $\varnothing(2000)$ The adaptive timing of diapause: a search for evolutionarily robust strategies in Calanus finmarchicus. ICES J Mar Sci 57:1825-1833

Fischer B, Dieckmann U, Taborsky B (2011) When to store energy in a stochastic environement. Evolution 65:1221-1232

Forrest J, Miller-Rushing AJ (2010) Toward a synthetic understanding of the role of phenology in ecology and evolution. Philos Trans R Soc Lond B 365:3101-3112

Gentleman WC, Pepin P, Doucette S (2012) Estimating mortality: clarifying assumptions and sources of uncertainty in vertical methods. J Mar Syst 105:1-19

Ghalambor CK, Martin TE (2001) Fecundity-survival trade-offs and parental risk-taking in birds. Science 292:494-497

Giacomini HC, Shuter BJ (2013) Adaptive responses of energy storage and fish life histories to climatic gradients. J Theor Biol 339:100-111

Hagen W, Schnack-Schiel SB (1996) Seasonal lipid dynamics in dominant Antarctic copepods: energy for overwintering or reproduction? Deep-Sea Research Part I 43:139-158

Hahn DA, Denlinger DL (2011) Energetics of insect diapause. Annu Rev Entomol 56:103-121

Haugen IMA, Gotthard K (2015) Diapause induction and relaxed selection on alternative developmental pathways in a butterfly. J Anim Ecol 84:464-472

Hays GC, Kennedy H, Frost BW (2001) Individual variability in diel vertical migration of a marine copepod: why some individuals remain at depth when others migrate. Limnol Oceanogr 46:2050-2054

Hind A, Gurney WSC, Heath M, Bryant AD (2000) Overwintering strategies in Calanus finmarchicus. Mar Ecol Prog Ser 193:95-107

Hirche HJ (1996) Diapause in the marine copepod Calanus finmarchicus: a review. Ophelia 44:129-143

Hirche HJ (2013) Long-term experiments on lifespan, reproductive activity and timing of reproduction in the Arctic copepod Calanus hyperboreus. Mar Biol 160:2469-2481

Hirche HJ, Kattner G (1993) Egg-production and lipid-content of Calanus glacialis in spring: indication of a food-dependent and food-independent reproductive mode. Mar Biol 117:615-622

Houston AI, McNamara JM (1999) Models of adaptive behaviour. Cambridge University Press, Cambridge

Houston AI, Stephens PA, Boyd IL et al (2007) Capital or income breeding? A theoretical model of female reproductive strategies. Behav Ecol 18:241-250

Javoiš J, Molleman F, Tammaru T (2011) Quantifying income breeding: using geometrid moths as an example. Entomol Exp Appl 139:187-196

Jervis MA, Ellers J, Harvey JA (2008) Resource acquisition, allocation, and utilization in parasitoid reproductive strategies. Annu Rev Entomol 53:361-385

Ji R (2011) Calanus finmarchicus diapause initiation: new view from traditional life history-based model. Mar Ecol Prog Ser 440:105-114 
Johnson CL, Leising AW, Runge JA et al (2008) Characteristics of Calanus finmarchicus dormancy patterns in the Northwest Atlantic. ICES J Mar Sci 65:339-350

Jónasdóttir SH, Visser AW, Richardson K, Heath MR (2015) Seasonal copepod lipid pump promotes carbon sequestration in the deep North Atlantic. Proc Natl Acad Sci USA 112:12122-12126

Jönsson KI (1997) Capital and income breeding as alternative tactics of resource use in reproduction. Oikos 78:57-66

Jørgensen C, Ernande B, Fiksen Ø, Dieckmann U (2006) The logic of skipped spawning in fish. Can J Fish Aquat Sci 63:200-211

Kaartvedt S (2000) Life history of Calanus finmarchicus in the Norwegian Sea in relation to planktivorous fish. ICES J Mar Sci 57:1819-1824

Kivelä SM, Välimäki P, Carrasco D et al (2012) Geographic variation in resource allocation to the abdomen in geometrid moths. Naturwissenschaften 99:607-616

Kozłowski J (2006) Why life histories are diverse. Pol J Ecol 54:585-605

Kroon A, Veenendaal RL (1998) Trade-off between diapause and other life-history traits in the spider mite Tetranychus urticae. Ecol Entomol 23:298-304

Kroon A, Veenendaal RL, Bruin J et al (2004) Predation risk affects diapause induction in the spider mite Tetranychus urticae. Exp Appl Acarol 34:307-314

Kroon A, Veenendaal RL, Bruin J et al (2008) "Sleeping with the enemy"-predator-induced diapause in a mite. Naturwissenschaften 95:1195-1198

Lass S, Spaak P (2003) Chemically induced anti-predator defences in plankton: a review. Hydrobiologia 491:221-239

Lillehammer A, Brittain JE, Saltveit SJ, Nielsen PS (1989) Egg development, nymphal growth and life cycle strategies in Plecoptera. Holarct Ecol 12:173-186

Lima SL, Dill LM (1990) Behavioral decisions made under the risk of predation: a review and prospectus. Can J Zool 68:619-640

Liu ZD, Gong PY, Wu KJ et al (2007) Effects of larval host plants on over-wintering preparedness and survival of the cotton bollworm, Helicoverpa armigera (Hubner) (Lepidoptera: Noctuidae). J Insect Physiol 53:1016-1026

Maps F, Plourde S, Zakardjian B (2010) Control of dormancy by lipid metabolism in Calanus finmarchicus: a population model test. Mar Ecol Prog Ser 403:165-180

McBride RS, Somarakis S, Fitzhugh GR et al (2015) Energy acquisition and allocation to egg production in relation to fish reproductive strategies. Fish Fish 16:23-57

McNamara JM, Houston AI (2008) Optimal annual routines: behaviour in the context of physiology and ecology. Philos Trans R Soc Lond B 363:301-319

Miller CB, Frost BW, Batchelder HP et al (1984) Life histories of large, grazing copepods in a subarctic ocean gyre: Neocalanus plumchrus, Neocalanus cristatus, and Eucalanus bungii in the Northeast Pacific. Prog Oceanogr 13:201-243

Morata N, Søreide JE (2015) Effect of light and food on the metabolism of the Arctic copepod Calanus glacialis. Polar Biol 38:67-73

Morewood WD, Ring RA (1998) Revision of the life history of the High Arctic moth Gynaephora groenlandica (Wocke) (Lepidoptera: Lymantriidae). Can J Zool 76:1371-1381

Niehoff B, Hirche HJ (2005) Reproduction of Calanus glacialis in the Lurefjord (western Norway): indication for temperature-induced female dormancy. Mar Ecol Prog Ser 285:107-115

Ohman MD, Frost BW, Cohen EB (1983) Reverse diel vertical migration-an escape from invertebrate predators. Science 220:1404-1407

Ohman MD, Drits AV, Clarke ME, Plourde S (1998) Differential dormancy of co-occurring copepods. Deep-Sea Res Part II 45:1709-1740

Pasternak AF, Kosobokova KN, Drits AV (1994) Feeding, metabolism and body composition of the dominant Antarctic copepods with comment on their life cycles. Russ J Aquat Ecol 3:49-62

Peckarsky BL, Taylor BW, McIntosh AR et al (2001) Variation in mayfly size at metamorphosis as a developmental response to risk of predation. Ecology 82:740-757

Peijnenburg KTCA, Goetze E (2013) High evolutionary potential of marine zooplankton. Ecol Evol 3:2765-2781

Remmel T, Davison J, Tammaru T (2011) Quantifying predation on folivorous insect larvae: the perspective of life-history evolution. Biol J Linn Soc 104:1-18

Rey-Rassat C, Irigoien X, Harris R, Carlotti F (2002) Energetic cost of gonad development in Calanus finmarchicus and C. helgolandicus. Mar Ecol Prog Ser 238:301-306

Reznick DN, Braun B (1987) Fat cycling in the mosquitofish (Gambusia affinis): fat storage as a reproductive adaptation. Oecologia 73:401-413 
Reznick DA, Bryga H, Endler JA (1990) Experimentally induced life-history evolution in a natural population. Nature 346:357-359

Roff D (1980) Optimizing development time in a seasonal environment: the 'ups and downs' of clinal variation. Oecologia 45:202-208

Roff DA (2002) Life history evolution. Sinauer Associates, Sunderland

Sainmont J, Andersen KH, Varpe Ø, Visser AW (2014) Capital versus income breeding in a seasonal environment. Am Nat 184:466-476

Schmid MS, Maps F, Fortier L (2018) Lipid load triggers migration to diapause in Arctic Calanus copepods-insights from underwater imaging. J Plankton Res 40:311-325

Slusarczyk M, Ochocka A, Biecek P (2013) Prevalence of kairomone-induced diapause in Daphnia magna from habitats with and without fish. Hydrobiologia 715:225-232

Stearns SC (1992) The evolution of life histories. Oxford University Press, Oxford

Stephens PA, Boyd IL, McNamara JM, Houston AI (2009) Capital breeding and income breeding: their meaning, measurement, and worth. Ecology 90:2057-2067

Stephens PA, Houston AI, Harding KC et al (2014) Capital and income breeding: the role of food supply. Ecology 95:882-896

Tammaru T, Haukioja E (1996) Capital breeders and income breeders among Lepidoptera: consequences to population dynamics. Oikos 77:561-564

Tauber MJ, Tauber CA, Masaki S (1986) Seasonal adaptations of insects. Oxford University Press, New York

Teder T, Esperk T, Remmel T et al (2010) Counterintuitive size patterns in bivoltine moths: late-season larvae grow larger despite lower food quality. Oecologia 162:117-125

Varpe $\varnothing$ (2012) Fitness and phenology: annual routines and zooplankton adaptations to seasonal cycles. J Plankton Res 34:267-276

Varpe $\varnothing$ (2017) Life history adaptations to seasonality. Integr Comp Biol 57:943-960

Varpe Ø, Ejsmond MJ (2018) Semelparity and Iteroparity. In: Wellborn G, Thiel M (eds) Natural history of crustacea. Life histories, vol 5. Oxford University Press, Oxford, pp 97-124

Varpe Ø, Jørgensen C, Tarling GA, Fiksen $\emptyset$ (2007) Early is better: seasonal egg fitness and timing of reproduction in a zooplankton life-history model. Oikos 116:1331-1342

Varpe $\varnothing$, Jørgensen C, Tarling GA, Fiksen $\varnothing$ (2009) The adaptive value of energy storage and capital breeding in seasonal environments. Oikos 118:363-370

Varpe Ø, Daase M, Kristiansen T (2015) A fish-eye view on the new Arctic lightscape. ICES J Mar Sci 72:2532-2538

Vogedes D, Varpe $\varnothing$, Søreide JE et al (2010) Lipid sac area as a proxy for individual lipid content of arctic calanoid copepods. J Plankton Res 32:1471-1477

Vogt G (2012) Ageing and longevity in the Decapoda (Crustacea): a review. Zool. Anz. 251:1-25

Walczyńska A (2010) Is wood safe for its inhabitants? Bull Entomol Res 100:461-465

Walczynska A, Danko M, Kozlowski J (2010) The considerable adult size variability in wood feeders is optimal. Ecol. Entomol. 35:16-24

Werner EE, Anholt BR (1993) Ecological consequences of the trade-off between growth and mortality rates mediated by foraging activity. Am Nat 142:242-272

Williams GC (1966) Natural selection, the costs of reproduction, and a refinement of Lack's principle. Am Nat 100:687-690

Williams CT et al (2017) Seasonal reproductive tactics: annual timing and the capital-to-income breeder continuum. Philos Trans R Soc Lond B 372:20160250

Ydenberg RC (1989) Growth-mortality trade-offs and the evolution of juvenile life histories in the Alcidae. Ecology 70:1494-1506 